\title{
Sodium selenite induces apoptosis and inhibits autophagy in human synovial sarcoma cell line SW982 in vitro
}

\author{
LE YANG $^{1}$, YONG-SONG CAI ${ }^{1}, \mathrm{KE} \mathrm{XU}^{1}$, JIA-LIN ZHU $^{1}$, YUAN-BO LI $^{1}$, \\ XIAO-QING WU ${ }^{1}$, JIAN SUN ${ }^{2}$, SHE-MIN LU ${ }^{2}$ and PENG XU ${ }^{1}$ \\ ${ }^{1}$ Department of Joint Surgery, Xi'an Hong Hui Hospital, Xi'an Jiaotong University Health \\ Science Center, Xi'an, Shaanxi 710054; ${ }^{2}$ Department of Genetics and Molecular Biology, \\ Xi'an Jiaotong University Health Science Center, Xi'an, Shaanxi 710061, P.R. China
}

Received December 4, 2016; Accepted February 12, 2018

DOI: $10.3892 / \mathrm{mmr} .2018 .8679$

\begin{abstract}
The present study aimed to examine the effects of sodium selenite on the SW982 human synovial sarcoma cell line in relation to cell viability, apoptosis and autophagy. The results indicated that sodium selenite reduced cell viability and induced apoptosis by activating caspase- 3 and members of the poly (ADP-ribose) polymerase and $\mathrm{Bcl}-2$ protein families in SW982 cells. Furthermore, autophagy was also suppressed by sodium selenite treatment in SW982 cells, and apoptosis was upregulated in cells co-treated with sodium selenite and the autophagy inhibitor 3-methyladenine. By contrast, apoptosis was downregulated when sodium selenite was combined with rapamycin, an inducer of autophagy. The results indicated that autophagy may protect cells from the cytotoxicity of sodium selenite. The present study results demonstrated that sodium selenite induced apoptosis and inhibited autophagy and autophagy-protected cells from death by antagonizing sodium selenite-induced apoptosis in SW982 cells in vitro.
\end{abstract}

\section{Introduction}

Synovial sarcoma is a high-grade soft tissue sarcoma that may occur in various regions of the body, particularly in para-articular regions; it is the fourth most common tumor of soft tissues, accounting for 5-10\% of all soft tissue sarcomas (1). Although the available treatments have improved, $25 \%$ of patients will succumb to synovial sarcoma within the first 5 years following diagnosis (2). Surgery is the main treatment for synovial sarcoma $(3,4)$; however, a previous study reported that postoperative chemotherapy for synovial sarcoma may effectively inhibit tumor growth (5), and thus postoperative

Correspondence to: Professor Peng Xu, Department of Joint Surgery, Xi'an Hong Hui Hospital, Xi'an Jiaotong University Health Science Center, 76 Nanguo Road, Xi'an, Shaanxi 710054, P.R. China E-mail: sousou369@163.com

Key words: synovial sarcoma, SW982 cell line, sodium selenite, apoptosis, autophagy chemotherapy for survival is necessary. The combination of surgery and chemotherapy has resulted in an $\sim 60 \%$ 5-year survival rate, yet the 10 -year survival rate remains low (1). As a result, it is essential for additional studies to identify novel chemotherapeutic drugs for synovial sarcoma therapy.

Selenium is an essential trace element that serves important roles in different physiological functions in the human body (6). Numerous epidemiological and clinical studies have suggested that physiological levels of selenium may have a wide range of biological effects, including strong protective effects against heart disease and age-related diseases $(7,8)$. Additional studies have indicated that physiological and supranutritional selenium exhibit chemopreventive or therapeutic activities on human solid cancers, such as lung cancer, colorectal cancer and leukemia, by inducing apoptosis in cancer cells with minimal side effects to normal cells, within a proper dose range (9-12). Pharmacokinetics and toxicity of sodium selenite have been reported in the treatment of patients with carcinoma in a phase I clinical trial (13). Therefore, selenium may serve as a potential auxiliary chemotherapeutic drug for synovial sarcoma in the future by initiating cancer cell apoptosis.

Apoptosis is an important biological process that leads to programmed cell death through the regulation of apoptosis-related gene expression, and serves an important role in a variety of tumor cells (14). Apoptosis is mediated by the regulation of numerous proteins, such as the apoptosis regulator Bcl-2 (Bcl-2) protein family and caspases. Bcl-2 inhibits the induction of apoptosis, and $\mathrm{Bcl}-2$-associated $\mathrm{X}$ protein (Bax) induces apoptosis. High expression of Bcl-2 affects the susceptibility of cells to the induction of apoptosis and is often associated with low expression of Bax (15). Bcl-2 and other Bcl-2 protein family members target intracellular organelles, including the endoplasmic reticulum as well as outer mitochondrial and nuclear membranes, where they modulate responses to a number of cell death stimuli (15). Damage to the outer mitochondrial membrane subsequently results in increased permeability and the release of apoptosis-associated molecules (16). These molecules subsequently activate apoptotic factors, such as Caspase (Casp)-9 and its downstream factors, Casp-3 and poly (ADP-ribose) polymerase (PARP) (16). However, the mechanisms by which selenium activates apoptotic machinery are not well understood. Autophagy is 
a survival strategy that is used by cells experiencing nutrient deprivation or other stresses, and is widely involved in the pathogenesis of many diseases, cancer in particular $(17,18)$. During autophagy, cytoplasmic material is sequestered into double-membrane vesicles, autophagosomes, which fuse with lysosomes and their contents are subsequently degraded and recycled. Beclin-1 and microtubule-associated protein 1 light chain 3 (LC3) are markers of autophagy: Beclin-1 is associated with the trafficking of lysosomal enzymes to lysosomes as well as autophagic vesicle nucleation, and LC3, particularly LC3-II, is a marker of autophagosome formation (19). In addition, autophagy is responsible for the degradation of p62, which is a selective autophagy receptor for the degradation of ubiquitinated substrates (19). However, different studies report different results regarding the role of selenium in tumor cell autophagy. Selenium was reported to inhibit autophagy in leukemia cells (20), whereas in lung cancer and certain other tumors, selenium was revealed to promote tumor cell autophagy $(10,21)$. Therefore, it is difficult to draw a conclusion regarding the effects of selenium on tumor cell autophagy, particularly in synovial sarcoma cells. The individual roles of apoptosis and autophagy, and the interplay between these processes are complex and may be different in different cells as well as in relation to various stressors. On the one hand, a previous study indicated that autophagy may protect certain tumor cells from chemotherapy drug-induced apoptosis in vivo and in vitro (22). On the other hand, extensive or persistent autophagy may also induce cell death; this autophagic cell death is termed type II programmed cell death $(23,24)$. Thus, autophagy may serve as an adapter between cell death and survival (25). Limited evidence is available regarding the roles of selenium on the underlying mechanisms in human tumor cells, and the effects of sodium selenite, an inorganic selenium compound, in synovial sarcoma cells have not been reported.

The aims of the present study were to determine the mode of action of sodium selenite in the context of its antitumor activity on synovial sarcoma, to investigate the relationship between apoptosis and autophagy, and to examine the molecular mechanisms underlying sodium selenite treatment in cancer cells. Results from the present study may provide the first evidence to suggest that sodium selenite induces apoptosis and inhibits autophagy in SW982 cells in vitro. These observations demonstrated that sodium selenite may serve as a novel adjuvant therapy in the treatment of synovial sarcoma.

\section{Materials and methods}

Cells and main reagents. The SW982 human synovial sarcoma cell line was obtained from The Cell Bank of Type Culture Collection of the Chinese Academy of Sciences (Shanghai, China). Sodium selenite was purchased from Sigma-Aldrich (Merck KGaA, Darmstadt, Germany). LC3 (cat. no. L7541) and p62 (cat. no. p0067) antibodies were purchased from Sigma-Aldrich; Merck KGaA. The $\beta$-actin (cat. no. bs-0061R) antibody was purchased from Biosen Biotech Company (Beijing, China). Pro-Caspase (Casp)-3 (cat. no. ab32351), cleaved-Casp-3 (cat. no. ab207612), PARPp85 (cat. no. ab32561) and Bcl-2 (cat. no. ab32124) antibodies were purchased from Abcam (Cambridge, UK). Beclin-1 (cat. no. 3738) and Bax (cat. no. 2772) antibodies were purchased from Cell Signaling
Technology, Inc. (Danvers, MA, USA). 3-methyladenine (3-MA) was purchased from Selleck Chemicals (Shanghai, China). Rapamycin was purchased from Sigma-Aldrich; Merck KGaA. Fluorescein isothiocyanate-conjugated immunoglobulin $\mathrm{G}$ ( $\mathrm{IgG}$ ) was purchased from Thermo Fisher Scientific, Inc. (Waltham, MA, USA). Bovine serum albumin was purchased from Sigma-Aldrich; Merck KGaA.

Cell culture and treatment. SW982 cells were cultured in Dulbecco's modified Eagle medium/Ham's Nutrient Mixture F12 medium (Thermo Fisher Scientific, Inc.) containing 10\% fetal bovine serum (Gibco; Thermo Fisher Scientific, Inc.), penicillin $\mathrm{G}(100 \mathrm{U} / \mathrm{ml})$, and streptomycin $(100 \mu \mathrm{g} / \mathrm{ml})$ in a $5 \% \mathrm{CO}_{2}$-humidified atmosphere at $37^{\circ} \mathrm{C}$. A previous study suggested that the reference range for blood selenium level was 80-150 $\mu \mathrm{g} / \mathrm{l}$ (1.02-1.91 $\mu \mathrm{mol} / \mathrm{l})$ (26); blood selenium concentrations of $1,400 \mathrm{ng} / \mathrm{ml}$ (equivalent to $17.7 \mu \mathrm{M}$ ) are toxic and may cause symptoms of selenium poisoning, including hair and nail loss, disorders of the respiratory system and paralysis $(27,28)$. Therefore, the present study used non-toxic sodium selenite concentrations $(0,5,10$ and $15 \mu \mathrm{M})$ and toxic sodium selenite concentrations (20 and $30 \mu \mathrm{M})$ for investigation. The culture periods ranged between 0 and $72 \mathrm{~h}$ of continuous exposure to sodium selenite.

Inhibition of autophagy. SW982 cells $\left(5 \times 10^{4}\right.$ cells $\left./ \mathrm{ml}\right)$ were seeded into 6 -well plates and then incubated in a $5 \%$ $\mathrm{CO}_{2}$-humidified atmosphere at $37^{\circ} \mathrm{C}$. Following overnight incubation, SW982 cells were pretreated with an autophagy inhibitor, 3-MA (5 mM) for $2 \mathrm{~h}$ and subsequently incubated with sodium selenite $(10 \mu \mathrm{M})$ for $24 \mathrm{~h}$ at $37^{\circ} \mathrm{C}$.

Induction of autophagy. SW982 cells $\left(5 \times 10^{4}\right.$ cells $\left./ \mathrm{ml}\right)$ were seeded into 6 -well plates and then incubated in a $5 \%$ $\mathrm{CO}_{2}$-humidified atmosphere at $37^{\circ} \mathrm{C}$. Following overnight incubation, SW982 cells were pretreated with $100 \mathrm{nM}$ rapamycin for $2 \mathrm{~h}$ at $37^{\circ} \mathrm{C}$ and subsequently incubated at $37^{\circ} \mathrm{C}$ with sodium selenite $(10 \mu \mathrm{M})$ for $24 \mathrm{~h}$.

Cell viability experiments. Cell viability was measured using the 3-(4,5-dimethylthiazol-2-yl)-2,5-diphenyltetrazolium bromide (MTT) assay. Briefly, SW982 cells $\left(5 \times 10^{4}\right.$ cells $\left./ \mathrm{ml}\right)$ were seeded into 96 -well plates, incubated in a $5 \% \mathrm{CO}_{2}$-humidified atmosphere at $37^{\circ} \mathrm{C}$ overnight and exposed to concentrations of sodium selenite ranging between 0 and $30 \mu \mathrm{M}$ for $0-72 \mathrm{~h}$ at $37^{\circ} \mathrm{C}$. Following incubations, MTT solution $(20 \mu \mathrm{l} ; 5 \mathrm{mg} / \mathrm{ml})$ was added to each well, and the cells were incubated for an additional $4 \mathrm{~h}$ at $37^{\circ} \mathrm{C}$. Following removal of the remaining medium, dimethyl sulfoxide $(150 \mu \mathrm{l})$ was added to each well to solubilize the precipitate. The optical density (OD) was measured at $570 \mathrm{~nm}$ with a microplate reader (Thermo Fisher Scientific, Inc.), and the following formula was used to calculate viability: Cell viability $(\%)=(\mathrm{OD}$ of the experimental sample/OD of the control group) $\mathrm{x} 100$. The half maximal inhibitory concentrations $\left(\mathrm{IC}_{50}\right)$ were determined using GraphPad Prism 5.0 statistical software (GraphPad Software, Inc., La Jolla, CA, USA).

Morphological changes in SW982 cells assay. SW982 cells $\left(5 \times 10^{4}\right.$ cells $\left./ \mathrm{ml}\right)$ were incubated in 96 -well plates with either various concentrations $(0,5,10$ and $15 \mu \mathrm{M})$ of sodium selenite 
for $24 \mathrm{~h}$ or with $10 \mu \mathrm{M}$ sodium selenite for various lengths of time $(0,6,12$ and 24 h). Morphological changes of SW982 cells were determined using an inverted microscope (Nikon Corporation, Tokyo, Japan). The morphological changes of SW982 cells include cell density, cell deformation and cell pycnosis.

Apoptosis detection. Following the treatments with various concentration or length of exposure to sodium selenite at $37^{\circ} \mathrm{C}$, SW982 cells $\left(5 \times 10^{4}\right.$ cells $\left./ \mathrm{ml}\right)$ were detached with trypsin, washed twice with 1X PBS and resuspended in annexin V binding buffer (200 $\mu$; 7SeaPharmTech, Shanghai, China). Subsequently, cells were incubated with annexin V-fluorescein isothiocyanate (7SeaPharmTech) for $15 \mathrm{~min}$ at room temperature in the dark, followed by propidium iodide (7SeaPharmTech) for $5 \mathrm{~min}$ at $4^{\circ} \mathrm{C}$ in the dark. Apoptotic cells were analyzed using a Guava EasyCyteHT flow cytometer (Merck KGaA).

Transmission electron microscopy (TEM) analysis of autophagy. Following the various treatments, SW982 cells $\left(5 \times 10^{4}\right.$ cells $\left./ \mathrm{ml}\right)$ were detached with trypsin, washed twice with PBS and fixed in ice-cold $2 \%$ glutaraldehyde/ $0.1 \mathrm{M}$ phosphate buffer ( $\mathrm{pH} 7.2$ ) for $2 \mathrm{~h}$ at $4^{\circ} \mathrm{C}$, post-fixed in $1 \%$ osmium tetroxide for $2 \mathrm{~h}$ at $4^{\circ} \mathrm{C}$, washed with PBS, dehydrated in a graded ethanol series $(30,50,70,90$ and $100 \%)$ at $4^{\circ} \mathrm{C}$ (each concentration for $10 \mathrm{~min}$ ) and embedded in 1:1 propylene oxide/embedding resin at $37^{\circ} \mathrm{C}$ for $24 \mathrm{~h}$. The resin blocks cut with a LKB-V microtome (LKB Bromma, Sollentuna, Sweden), and thin $(60 \mathrm{~nm})$ sections were picked up on 200-mesh copper grids and stained with uranyl acetate and lead citrate for $10 \mathrm{~min}$ at room temperature. The sections were examined with a H-7650 transmission electron microscope (Hitachi, Ltd., Tokyo, Japan).

LC3 immunofluorescence. SW982 cells $\left(5 \times 10^{4}\right.$ cells $\left./ \mathrm{ml}\right)$ were seeded into 24 -well plates and then incubated in a $5 \% \mathrm{CO}_{2}$-humidified atmosphere at $37^{\circ} \mathrm{C}$ overnight. Following overnight incubation, cells were treated with 0,10 and $15 \mu \mathrm{M}$ sodium selenite for $24 \mathrm{~h}$ at $37^{\circ} \mathrm{C}$. Subsequently, the medium was removed, cells were washed twice with PBS and then fixed with $3.7 \%$ paraformaldehyde and treated with $0.2 \%$ Triton X-100 to permeabilize for $30 \mathrm{~min}$ on ice. Following blocking with $2 \%$ bovine serum albumin for $1 \mathrm{~h}$ at room temperature, cells were subsequently incubated with LC3 antibodies [1:200 dilution with phosphate buffered saline with $0.1 \%$ Tween-20 (PBST)] for $2 \mathrm{~h}$, and then incubated withfluorescein isothiocyanate-conjugated immunoglobulin $\mathrm{G}$ (IgG; 1:100) with PBST for $1 \mathrm{~h}$ at room temperature. Following this, cells were incubated with Hoechst 33258 solution $(10 \mu \mathrm{g} / \mathrm{ml})$ for $15 \mathrm{~min}$ at room temperature. A fluorescence microscope (Nikon Corporation) was used to determine LC3 immunofluorescence (magnification, x200). A total of 5 fields of vision/per well were investigated.

Western blotting analysis. Following the various treatments and incubation in a $5 \% \mathrm{CO}_{2}$-humidified atmosphere at $37^{\circ} \mathrm{C}$, the medium was removed and SW982 cells were washed twice with cold PBS and solubilized in Triton lysis buffer (50 mM Tris-HCl, pH 7.4; 150 mM NaCl; 0.2 mM EDTA; $1 \%$ Triton $\mathrm{X}-100 ; 1 \%$ sodium deoxycholate and $0.1 \%$ SDS) and protease inhibitor cocktail (Beyotime Institute of
Biotechnology, Shanghai, China) on ice. Protein concentrations were determined using the Bicinchoninic Acid assay (Thermo Fisher Scientific, Inc.). The amount of supernatant loaded into each well was calculated according to the protein concentrations. Either $10 \%$ or $12 \%$ SDS-PAGE was prepared for western blotting analysis, and each well was loaded with $20 \mu \mathrm{g}$ of protein. Proteins were transferred onto an Immoblin-P nitrocellulose membrane (EMD Millipore, Billerica, MA, USA), blocked in $10 \%$ non-fat milk in Tris-buffered saline $+0.1 \%$ Tween-20 (TBST) for $2 \mathrm{~h}$ at room temperature and then incubated overnight at $4{ }^{\circ} \mathrm{C}$ with the following primary antibodies: Anti-Bax, 1:600; anti-Bcl-2, 1:100; anti-pro-caspase-3, 1:200; anti-cleaved-caspase-3, 1:200; anti-PARPp85, 1:200; anti-P62, 1:2,000; anti-Beclin-1, 1:500; anti-LC3-II, 1:500; and anti- $\beta$-actin, 1:750. Membranes were washed with TBST buffer and reacted with the appropriate horseradish peroxidase-conjugated secondary antibodies (goat anti-rabbit IgG; 1:10,000; Thermo Fisher Scientific, Inc.) for $1 \mathrm{~h}$ at room temperature. Following incubation with the secondary antibodies, the membranes were washed thrice with TBST and once with TBS and developed using an enhanced chemiluminescence kit (Thermo Fisher Scientific, Inc.) and a GeneGnome 5 western blotting detection system (Synoptics Ltd., Cambridge, UK). $\beta$-actin was used as the internal control and for the normalization of protein expression, and densitometric analysis was performed using Image J2 software (National Institutes of Health, Bethesda, MD, USA).

Statistical analysis. Data are presented as the mean \pm standard deviation; experiments were repeated thrice $(n=3)$. All statistical analyses of the experimental data were performed using GraphPad Prism 5.0 statistical software (GraphPad Software, La Jolla, CA, USA). Two-tailed Student's t-test was used to determine significant differences in the normal distribution of the data of the two groups. Data for multiple variable comparisons were analyzed by one-way analysis of variance or the Kruskal-Wallis test, which were then followed by the Bonferroni post-hoc test. $\mathrm{P}<0.05$ was considered to indicate a statistically significant difference.

\section{Results}

Sodium selenite reduces cell viability in SW982 human synovial sarcoma cells. The effects of sodium selenite on SW982 cell viability were examined with the MTT assay. SW982 cells were treated with sodium selenite at concentrations ranging between 0 and $30 \mu \mathrm{M}$, which included both nutritious and toxic doses, for 0 to $72 \mathrm{~h}$. The results indicated that sodium selenite significantly inhibited SW982 cell viability in a time- and dose-dependent manner (Fig. 1A). The $\mathrm{IC}_{50}$ values of $51.9 \pm 5.9 \mu \mathrm{M}$ at $3 \mathrm{~h}, \mathrm{IC}_{50}$ values of $37.3 \pm 2.8 \mu \mathrm{M}$ at $6 \mathrm{~h}, \mathrm{IC}_{50}$ values of $30.1 \pm 1.3 \mu \mathrm{M}$ at $12 \mathrm{~h}, \mathrm{IC}_{50}$ values of $26.8 \pm 1.0 \mu \mathrm{M}$ at $24 \mathrm{~h}, \mathrm{IC}_{50}$ values of $13.4 \pm 0.4 \mu \mathrm{M}$ at $48 \mathrm{~h}$ and $\mathrm{IC}_{50}$ values of $9.3 \pm 0.4 \mu \mathrm{M}$ at $72 \mathrm{~h}$ of treatment (Fig. 1B). Significant inhibitory effects were observed with $5 \mu \mathrm{M}$ or greater sodium selenite treatment for $12 \mathrm{~h}$; similarly, $\geq 10 \mu \mathrm{M}$ sodium selenite treatment for $3 \mathrm{~h}$ significantly inhibited cell viability. Furthermore, toxic doses $(>17.7 \mu \mathrm{M})$ of sodium selenite (24) also significantly inhibited cell viability (Fig. 1A). In addition, morphological changes in SW982 cells exposed to sodium selenite were observed: The 

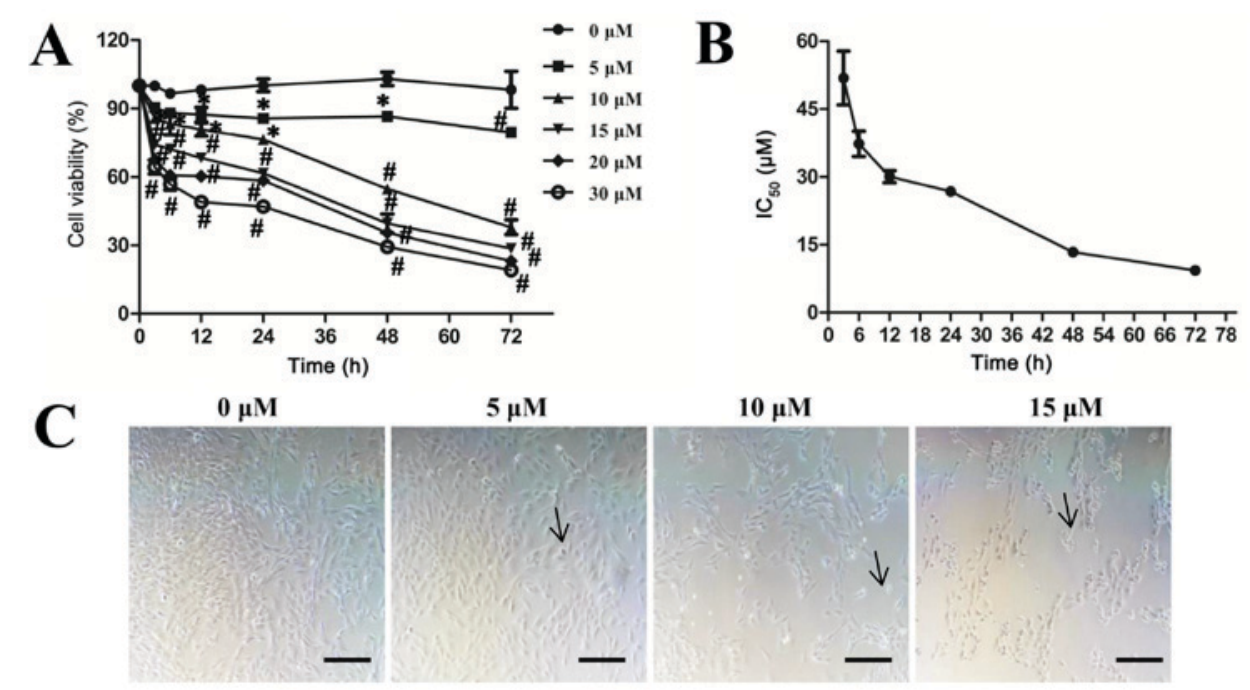

$10 \mu \mathrm{M}$

$15 \mu \mathrm{M}$

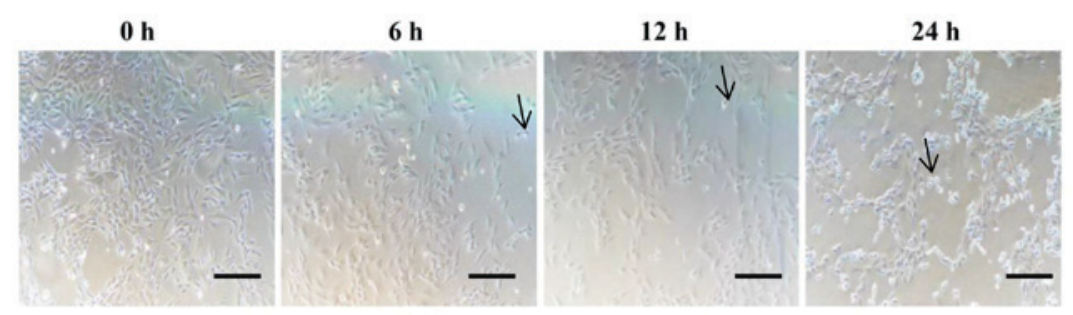

Figure 1. Sodium selenite inhibits cell viability in SW982 human synovial sarcoma cells. (A) SW982 cells were incubated with various concentrations $(0,5,10,15,20$ and $30 \mu \mathrm{M})$ of sodium selenite for 0 to $72 \mathrm{~h}$. Cell viability was determined using an MTT assay. (B) The $\mathrm{IC}_{50}$ of sodium selenite in SW982 cells. (C) SW982 cells were incubated with various concentrations $(0,5,10$ and $15 \mu \mathrm{M})$ of sodium selenite for $24 \mathrm{~h}$ or with $10 \mu \mathrm{M}$ sodium selenite for various times $(0,6,12$ and $24 \mathrm{~h})$. Morphological changes in SW982 cells were determined by inverted microscopy; Scale bar, $50 \mu \mathrm{m}$. Data are presented as the mean \pm standard deviation of at least three independent experiments; ${ }^{*} \mathrm{P}<0.05$ and ${ }^{\sharp} \mathrm{P}<0.01$ vs. respective control group $(0 \mu \mathrm{M}$ or $0 \mathrm{~h})$.

cells shrunk, retracted from neighboring cells, lost their flat and polygonal shape and ultimately detached from the culture dish (arrow); thus suggesting that cell death was induced by sodium selenite (Fig. 1C). Following treatment with sodium selenite, the cell density was significantly decreased in a dose and time-dependent manner. These results indicated that sodium selenite inhibits cell viability in SW982 cells.

Sodium selenite induces apoptosis in SW982 cells by regulating expression of Casp-3,PARPp85 and Bcl-2/Bax proteins. The effects of sodium selenite on apoptosis in SW982 cells were examined by flow cytometry. The results indicated that sodium selenite treatment induced apoptosis in a time- and dose-dependent manner (Fig. 2A-C). To determine the mechanisms by which sodium selenite induced apoptosis, western blotting assays were used to analyze the expression levels of apoptosis-related proteins. The results demonstrated that sodium selenite treatment significantly reduced the expression of the anti-apoptotic protein Bcl-2 and pro-Casp-3 protein, and increased the expression of the pro-apoptotic protein Bax, cleaved-Casp-3 and PARPp85 in a time- and dose-dependent manner (Fig. 2D-F). These results revealed that sodium selenite induced apoptosis in SW982 cells through the activation of Casp-3, PARPp85, Bcl-2 and Bax proteins.

Sodium selenite inhibits autophagy in SW982 cells. The effects of sodium selenite on autophagy in SW982 cells were also examined. TEM results revealed that a higher number of autophagic vesicles formed in the untreated $(0 \mu \mathrm{M})$ control group compared with the number of autophagy vesicles that formed following treatment with $15 \mu \mathrm{M}$ sodium selenite (Fig. 1A). Cells treated with $10 \mu \mathrm{M}$ sodium selenite for $24 \mathrm{~h}$ also exhibited reduced formation of autophagic vesicles compared with the control group at $0 \mathrm{~h}$. The TEM results suggested that sodium selenite inhibited autophagy in SW982 cells (Fig. 3A).

Expression of the autophagy-related proteins LC3, Beclin-1 and p62 were examined by western blotting. The results revealed a significant decrease in the protein expression levels of LC3-II and Beclin-1, whereas the level of p62 expression was significantly increased in a dose- and time-dependent manner, compared with the respective untreated controls (Fig. 3B-D). Furthermore, LC3 immunofluorescence experiments were conducted to further verify the effects of sodium selenite on SW982 cell autophagy. The results demonstrated an enhanced expression of LC3 immunofluorescence visible in the untreated $(0 \mu \mathrm{M})$ control group compared with the groups treated with 10 and $15 \mu \mathrm{M}$ sodium selenite (Fig. 4). LC3 fluorescence demonstrated that the expression of LC3 was decreased following treatment with sodium selenite (Fig. 4). These results confirmed that sodium selenite treatment inhibited autophagy in SW982 cells.

Inhibition of autophagy enhances sodium selenite-induced apoptosis in SW982 cells. Based on the aforementioned results, the present study aimed to verify that sodium selenite induces apoptosis and inhibits autophagy in SW982 cells following treatment with sodium selenite and to determine the inter-relationship between apoptosis and autophagy. Therefore, 
A

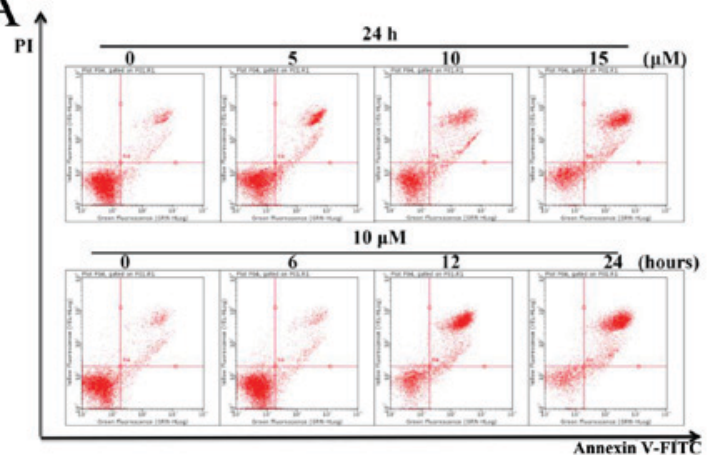

B

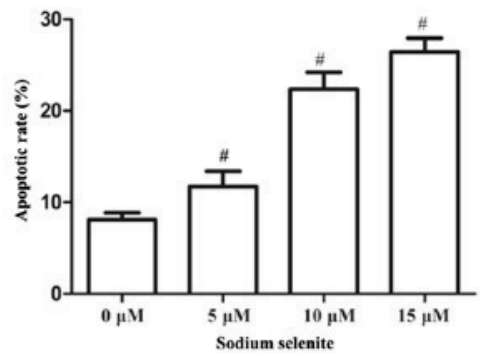

C

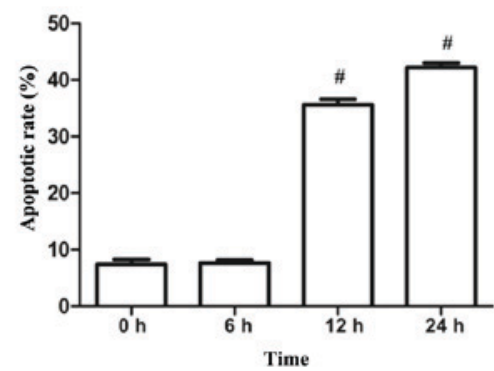

D

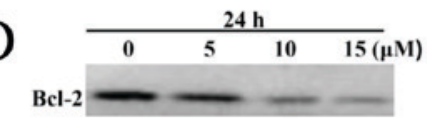

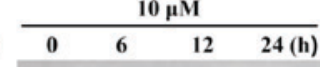

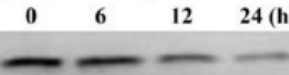

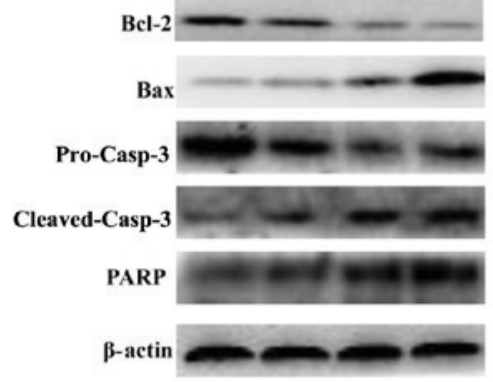

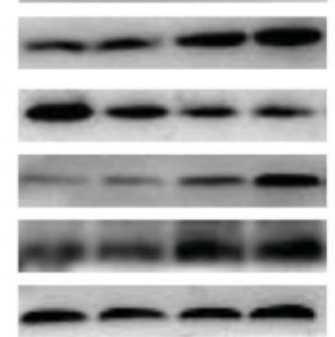

E
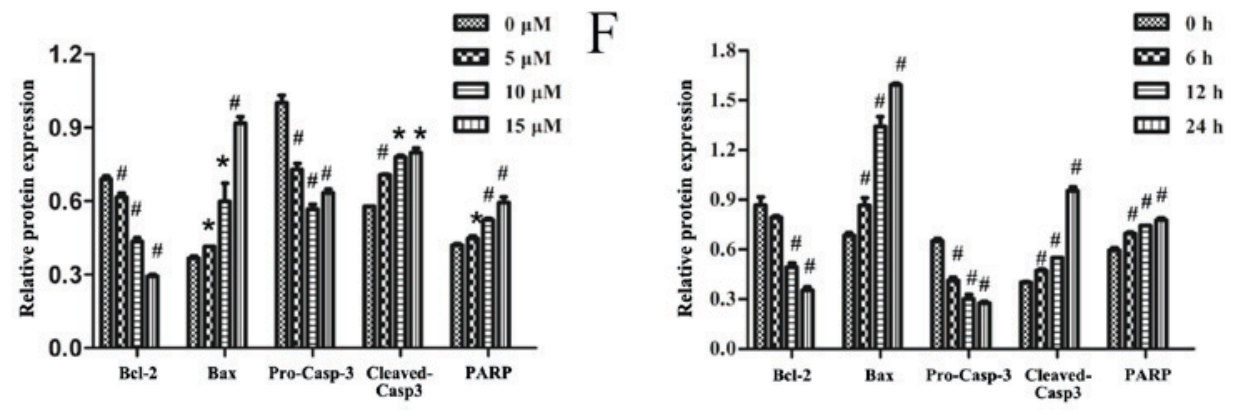

Figure 2. Sodium selenite induces apoptosis in SW982 cells via regulation of Casp-3, PARPp85, Bcl-2 and Bax protein expression. (A) Cells were treated with various concentrations $(0,5,10$ and $15 \mu \mathrm{M})$ of sodium selenite for $24 \mathrm{~h}$ or with $10 \mu \mathrm{M}$ sodium selenite for $0,6,12$ and $24 \mathrm{~h}$. Apoptotic rates were examined using an Annexin V-FITC/PI double-stain assay. Annexin V-FITC-positive and PI-negative stained cells indicate early apoptosis (lower right quadrant), Annexin V-FITC-positive and PI-positive double-stained cells indicate late apoptosis (upper right quadrant), and Annexin V-FITC-negative and PI-positive stained cells represent dead cells (upper left quadrant). (B and C) Apoptotic rates of SW982 cells analyzed by flow cytometry following treatment with either (B) various concentrations of sodium selenite or (C) various incubation times with $10 \mu \mathrm{M}$ sodium selenite. (D) Cell lysates were subjected to western blotting to determine the levels of apoptosis-related proteins Bcl-2, Bax, pro-Casp-3, cleaved-Casp-3 and PARP; $\beta$-actin was used as an internal control and to normalize the expression data. (E and F) Densitometric analysis of the apoptosis-related proteins from Part D. Data are presented as the mean \pm standard deviation of at least three independent experiments; ${ }^{*} \mathrm{P}<0.05$ and ${ }^{\sharp} \mathrm{P}<0.01$ vs. untreated control ( $0 \mu \mathrm{M}$ or $\left.0 \mathrm{~h}\right)$. Bax, Bcl-2-associated X protein; Casp, caspase; FITC, fluorescein isothiocyanate; PARP, poly (ADP-ribose) polymerase; PI, propidium iodide.

cells were incubated with 3-MA, an inhibitor of autophagy. TEM results indicated that 3 -MA inhibited autophagy in SW982 cells (Fig. 5A). Western blotting assays also confirmed that 3-MA inhibited autophagy by altering the expression of LC3-II (Fig. 5B and C). Thus, we clearly demonstrated that autophagy was inhibited by 3-MA. In addition, western blotting demonstrated that sodium selenite treatment in combination with 3-MA resulted in a significant decrease in the expression of anti-apoptotic protein Bcl-2 and significant increase in the expression of pro-apoptotic protein Bax compared with cells treated with sodium selenite alone (Fig. 5B, D and E).

MTT experiments revealed that cell viability was significantly reduced when cells were co-treated with sodium selenite and 3-MA compared with treatment with sodium selenite alone
(Fig. 5F). Furthermore, flow cytometric analyses revealed that cells treated with sodium selenite combined with 3-MA exhibited a significantly increased apoptotic rate compared with treatment with sodium selenite alone (Fig. 5G).

It was also demonstrated that upon stimulation of autophagy by rapamycin treatment, selenite-mediated cytotoxicity and apoptosis was significantly reduced compared with untreated cells (Fig. 6). Following treatment with sodium selenite+ $100 \mathrm{nM}$ rapamycin, the induction of autophagy significantly promoted cell viability and decreased the rate of apoptosis compared with sodium selenite treatment alone (Fig. 6A and B, respectively). Western blotting results also indicated that sodium selenite+ $100 \mathrm{nM}$ rapamycin notably increased the expression of anti-apoptotic protein $\mathrm{Bcl}-2$ and decreased the 


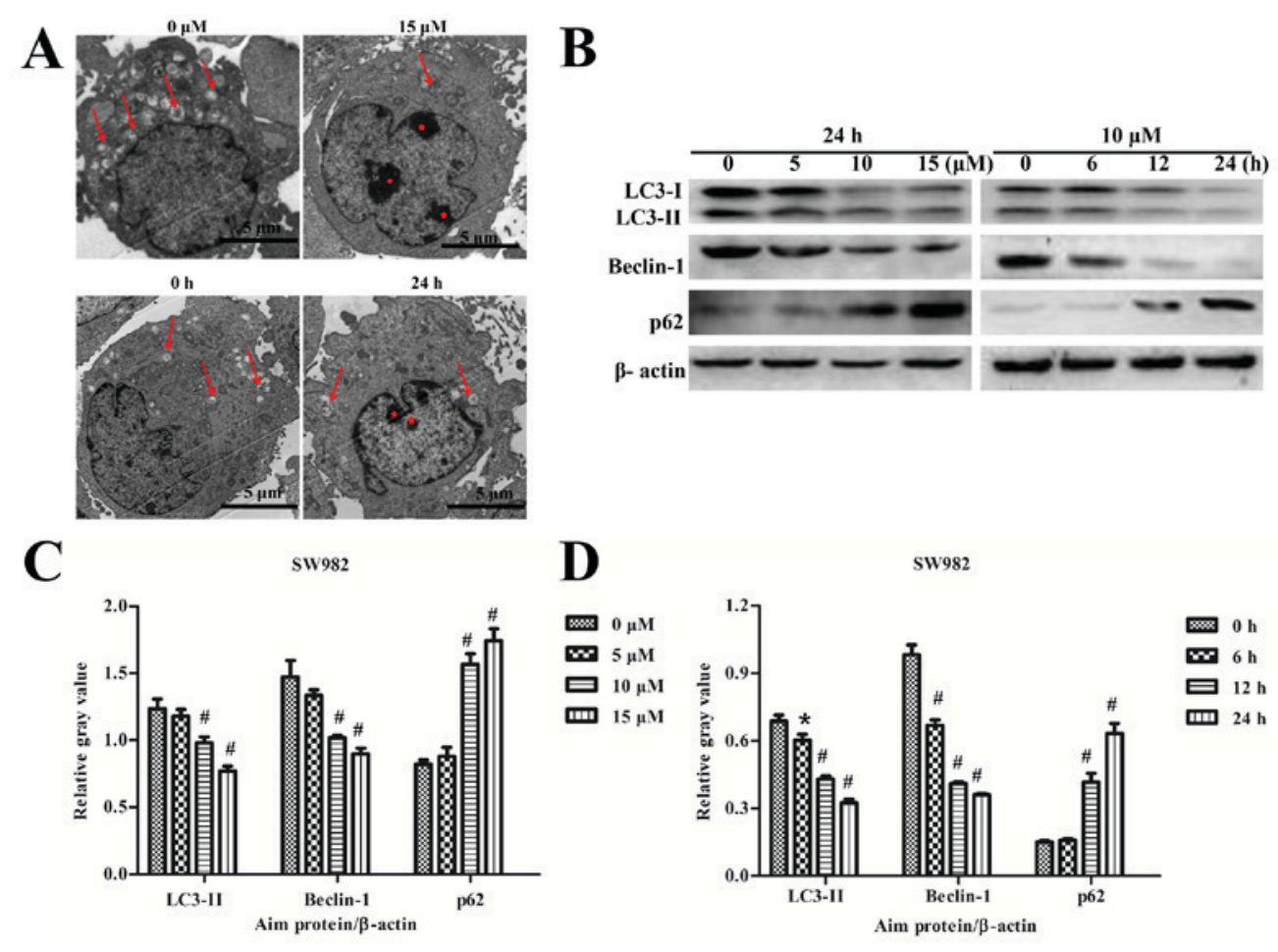

Figure 3. Sodium selenite inhibits autophagy in SW982 cells. (A) SW982 cells were treated with 0 or $15 \mu \mathrm{M}$ sodium selenite for $24 \mathrm{~h}$ or with $10 \mu \mathrm{M}$ sodium selenite for 0 and $24 \mathrm{~h}$. Autophagosomes (arrows) and nuclear condensation (asterisks) were assessed by electron microscopy; scale bar, $5 \mu \mathrm{m}$. (B) SW982 cells were treated with various concentrations $(0,5,10$ and $15 \mu \mathrm{M})$ of sodium selenite or with $10 \mu \mathrm{M}$ sodium selenite for $0,6,12$ and $24 \mathrm{~h}$. Cell lysates were subjected to western blotting to determine the effects of sodium selenite on the expression of autophagy regulatory proteins LC3, Beclin-1 and p62. (C and D) Densitometric analysis of autophagy-related proteins from Part B. Data are presented as the mean \pm standard deviation of at least three independent experiments; ${ }^{\mathrm{P}}<0.05$ and ${ }^{*} \mathrm{P}<0.01$ vs. untreated control $(0 \mu \mathrm{M}$ or $0 \mathrm{~h})$. LC3, microtubule-associated protein 1 light chain 3.
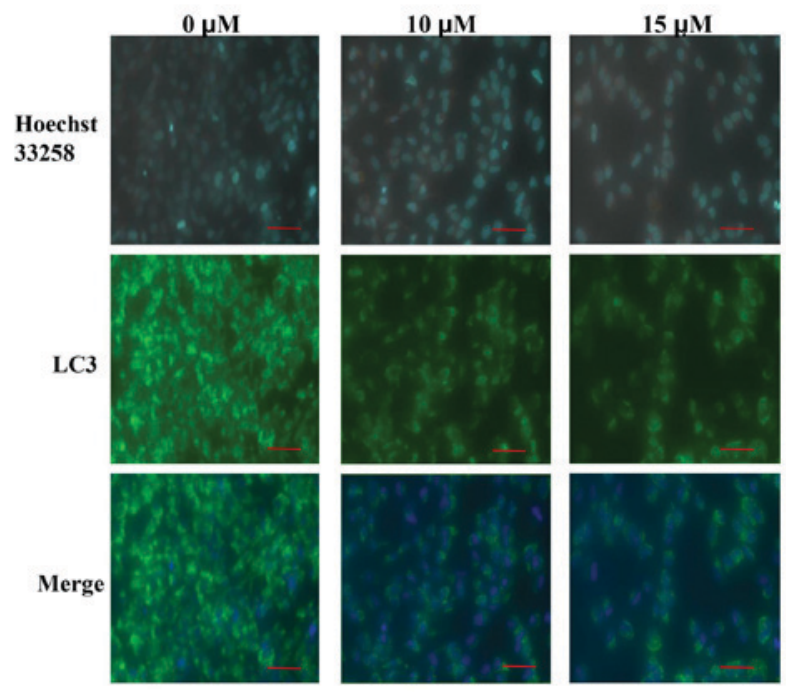

Figure 4. Sodium selenite inhibits LC3 expression in SW982 cells. SW982 cells were treated with 0,10 and $15 \mu \mathrm{M}$ sodium selenite for $24 \mathrm{~h}$. Cells were fixed and stained with an immunofluorescent anti-LC3 antibody (green), and cell nuclei were counterstained with Hoechst 33258 (blue); scale bar, $50 \mu \mathrm{m}$. Data are presented as the mean \pm standard deviation of at least three independent experiments. LC3, microtubule-associated protein 1 light chain 3.

expression of pro-apoptotic protein Bax compared with cells treated with sodium selenite alone (Fig. 6C and D).

Overall, these results indicated that suppression of autophagy may enhance sodium selenite-induced apoptosis in SW982 cells; therefore, autophagy may protect cells from death by antagonizing sodium selenite-induced apoptosis in SW982 cells.

\section{Discussion}

The effects of selenium on human synovial sarcoma have not been clearly elucidated. Given the antitumor effects of selenium, the present study was particularly interested in the effects of sodium selenite, an inorganic selenium compound, on the human synovial sarcoma cell line SW982. It was hypothesized that sodium selenite inhibited cell viability and induced apoptosis in SW982 cells; therefore the effects of sodium selenite exposure on cell viability were analyzed. The results demonstrated that sodium selenite significantly inhibited SW982 cell viability. Apoptosis serves a crucial role in a number of pathophysiological processes (15). Flow cytometry was used to observe that sodium selenite treatment significantly increased SW982 cell apoptosis via activation of Casp-3, PARPp85, Bcl-2 and Bax proteins. However, further studies are needed to determine the underlying mechanisms behind apoptosis. Autophagy is a cellular degradation pathway for the clearance of damaged or superfluous protein and organelles, and occurs in many tumor cells (19). Autophagy serves as a mechanism of cell survival by favoring stress adaptation over cell death (19). Excessive self-digestion and degradation of essential cellular components may induce what is known as autophagic cell death (19). The results of the present study demonstrated that sodium selenite inhibited autophagy in SW982 cells in vitro. The respective roles 

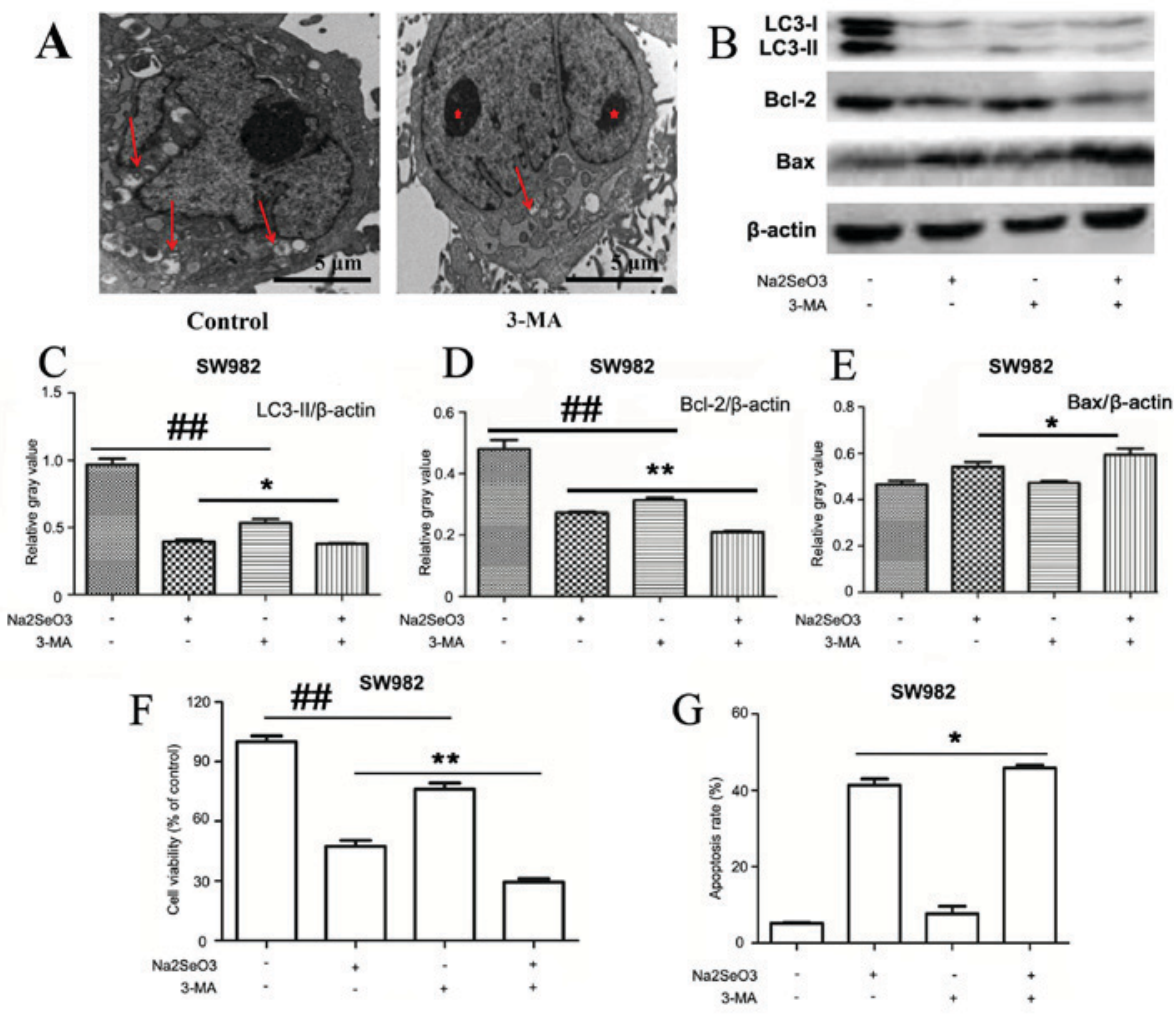

Figure 5. Inhibition of autophagy enhances sodium selenite-induced apoptosis in SW982 cells. SW982 cells were pretreated, 3-MA (5 mM), for $2 \mathrm{~h}$ and subsequently incubated with sodium selenite $(10 \mu \mathrm{M})$ for $24 \mathrm{~h}$. (A) Autophagosomes (arrows) and nuclear condensation (red asterisks) were examined by transmission electron microscopy; scale bar, $5 \mu \mathrm{m}$. (B) Cell lysates were subjected to western blotting to examine the expression levels of autophagy-related protein LC3 and apoptosis-related proteins Bcl-2 and Bax; $\beta$-actin was used as an internal control. Densitometric analysis of (C) LC3-II, (D) Bcl-2 and (E) Bax expression in SW982 cells treated with sodium selenite $(10 \mu \mathrm{M})$ in the absence or presence of 3-MA $(5 \mathrm{mM})$. (F) Cell viability was determined by using the MTT assay. (G) Apoptotic rates were measured by flow cytometry. Data are presented as the mean \pm standard deviation of at least three independent experiments; ${ }^{*} \mathrm{P}<0.05$ and ${ }^{* *} \mathrm{P}<0.01, \mathrm{Na}_{2} \mathrm{SeO}_{3}+3-\mathrm{MA}$ treated cells vs. $\mathrm{Na}_{2} \mathrm{SeO}_{3}$ treated cells; ${ }^{* \#} \mathrm{P}<0.01$, untreated cells vs. 3-MA treated cells. 3-MA, 3-methyladenine; Bax, Bcl-2-associated X protein; LC3, microtubule-associated protein 1 light chain $3 ; \mathrm{Na}_{2} \mathrm{SeO}_{3}$, sodium selenite.
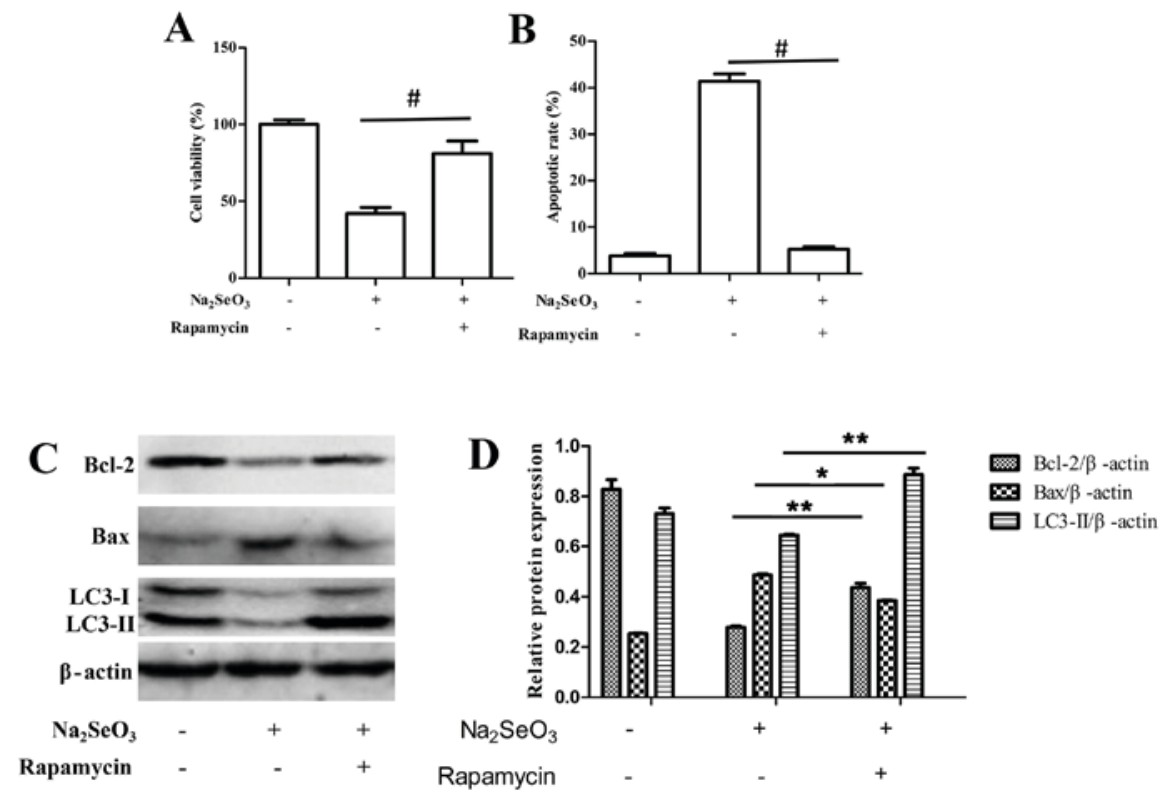

Figure 6. Induction of autophagy decreases sodium selenite-induced apoptosis in SW982 cells. SW982 cells were treated with sodium selenite (10 $\mu$ M) in the absence or presence of rapamycin $(100 \mathrm{nM})$. (A) Cell viability was measured by MTT assay. (B) Apoptotic rates were measured by flow cytometry. "P<0.01. (C) Cell lysates were subjected to western blotting and examined for the expression of apoptosis-related proteins Bcl-2 and Bax, and autophagy-related protein LC3; $\beta$-actin was used as an internal control. (D) Densitometric analysis of Bcl-2, Bax and LC3-II expression in SW982 cells were treated with sodium selenite $(10 \mu \mathrm{M})$ in the absence or presence of rapamycin $(100 \mathrm{nM}) .{ }^{*} \mathrm{P}<0.05$ and ${ }^{* *} \mathrm{P}<0.01, \mathrm{Na}_{2} \mathrm{SeO}_{3}+3-\mathrm{MA}$ treated cells vs. $\mathrm{Na}_{2} \mathrm{SeO}_{3}$ treated cells. Data are presented as the mean \pm standard deviation of at least three independent experiments. Bcl-2, B-cell lymphoma 2; Bax, Bcl-2-associated X protein; LC3, microtubule-associated protein 1 light chain $3 ; \mathrm{Na}_{2} \mathrm{SeO}_{3}$, sodium selenite. 
and interplay between apoptosis and autophagy are complex and may vary in different cells and in the context of various stress types. Previous observations indicated that autophagy serves a role in preventing apoptosis (22), whereas other studies reported that active autophagy increased apoptosis $(23,24)$. Several previous studies indicated that sodium selenite enhances, not suppresses, autophagic activity in certain types of cancer cells $(10,21)$. Thus, it is difficult to draw a conclusion regarding the effects of selenium on tumor cell autophagy. The mechanisms behind this observation are complex and require further investigation. The respective roles and the interplay between apoptosis and autophagy are complicated and are likely to vary in different cells and in response to different stressors. In the present study, autophagy was suppressed in sodium selenite-treated SW982 cells by co-treating cells with 3-MA, which significantly increased the apoptotic rates. In addition, apoptosis was downregulated when sodium selenite was combined with rapamycin, an inducer of autophagy. In summary, the data suggested that autophagy may protect SW982 cells from death by antagonizing sodium selenite-induced apoptosis; therefore, autophagy may play a protective role in SW982 cells.

The Akt/mammalian target of rapamycin (mTOR) signaling pathway is initiated by ligand-activated receptor tyrosine kinases on the plasma membrane, such as insulin-like growth factor 1 receptor and platelet-derived growth factor receptors, which recruit phosphatidylinositol 3-kinase (PI3K) directly to the receptor $(29,30)$. PI3K converts phosphatidylinositol 4,5-bisphosphate to phosphatidylinositol 3,4,5-triphosphate, which subsequently recruits Akt to the membrane, where it is activated and facilitates the downstream activation of mTOR (29). Akt/mTOR activation suppresses autophagy in mammalian cells, which suggested that inactivation of Akt/mTOR may promote autophagy (31). In addition, a previous study reported that the Akt/mTOR pathway positively regulates autophagy (32). A number of other previous studies indicated that sodium selenite exposure enhances autophagic activity in certain types of cancer cells $(10,21)$. Given the dual function of Akt/mTOR pathway in autophagy, the present study hypothesizes that the Akt/mTOR pathway may be involved in the inhibition of sodium selenite-induced autophagy in SW982 synovial sarcoma cells. A previous study using animal models with activated Akt demonstrated that oncogenesis through this pathway was dependent upon downstream activation of mTOR (33). Akt/mTOR pathway activation is associated with sarcoma oncogenesis through a number of mechanisms, such as: Mast/stem cell growth factor receptor Kit and platelet-derived growth receptor- $\alpha$ mutations in gastrointestinal stromal tumours; phosphatidylinositol 4,5-bisphosphate 3-kinase catalytic subunit- $\alpha$ isoform mutations in myxoid/round-cell liposarcomas; or other pathognomonic alterations that promote reliance upon the pathway, such as the dependence of RNA binding protein EWS-friend leukemia integration 1 transcription factor gene fusion-driven oncogenesis upon the IGF-1 receptor in Ewing sarcoma (29). Faghiri and Bazan (34) demonstrated that in single-dose oxidative stress-induced apoptosis, phosphorylation of Akt, mTOR, and p70S6K is both time- and dose-dependent. Furthermore, it has been demonstrated that wortmannin (a PI3K inhibitor that functions upstream of $\mathrm{Akt}$ ) and rapamycin (mTOR inhibitor that functions upstream in the
mTOR/p70S6K pathway) inhibit the PI3K and mTOR/p70S6K pathways, respectively, increase the apoptosis of human retinal pigment epithelial cells, and inhibits the phosphorylation of Akt and p70S6K otherwise induced by single-dose oxidative stress (34). Thus, the Akt/mTOR pathway maybe associated with both apoptosis and autophagy and may serve an important role in sodium selenite-induced apoptosis and autophagy suppression in SW982 cells. However, the underlying mechanisms require further research.

The characteristics of synovial sarcoma cells significantly differ from one cell line to another. Therefore, the results obtained from a single cell line may not always be interpreted as representing the biology of synovial sarcoma. In this regard, at least 3-4 different cell lines should be used to verify that sodium selenite may serve as a potential adjuvant agent for the treatment of synovial sarcoma. Over the course of this study, additional cell lines could not be obtained, as only one synovial sarcoma cell line exists in China. Future studies should use an alternative cell line of synovial sarcoma to verify the present study results.

\section{Acknowledgements}

Not applicable.

\section{Funding}

This study was supported by The National Natural Science Foundations of China (grant nos. 81271948 and 81601877).

\section{Availability of data and materials}

All data generated or analyzed during this study are included in this published article.

\section{Authors' contributions}

LY, YsC, KX and PX conceived and designed the experiments. LY and YsC performed the experiments. LY, JlZ, YL, XW, JS and SmL analyzed the data. LY wrote the manuscript. All authors read and approved the final manuscript.

\section{Ethics approval and consent to participate}

Not applicable.

\section{Consent for publication}

Not applicable.

\section{Competing interests}

The authors declare that they have no competing interests.

\section{Reference}

1. Minami Y, Kohsaka S, Tsuda M, Yachi K, Hatori N, Tanino M, Kimura T, Nishihara H, Minami A, Iwasaki N and Tanaka S: SS18-SSX-regulated miR-17 promotes tumor growth of synovial sarcoma by inhibiting p21WAF1/CIP1. Cancer Sci 105: 1152-1159, 2014. 
2. Ito T, Ouchida M, Morimoto Y, Yoshida A, Jitsumori Y, Ozaki T, Sonobe $\mathrm{H}$, Inoue $\mathrm{H}$ and Shimizu K: Significant growth suppression of synovial sarcomas by the histone deacetylase inhibitor FK228 in vitro and in vivo. Cancer Lett 224: 311-319, 2005.

3. Sun Y, Wang H, Lin F, Hua J and Zhou G: Inhibition of proliferation and gene expression regulation by (-)-epigallocatechin-3-gallate in human synovial sarcoma cells. Med Oncol 28: 1463-1468, 2011.

4. Haldar M, Randall RL and Capecchi MR: Synovial sarcoma: From genetics to genetic-based animal modeling. Clin Orthop Relat Res 466: 2156-2167, 2008.

5. Eilber FC, Brennan MF, Eilber FR, Eckardt JJ, Grobmyer SR, Riedel E, Forscher C, Maki RG and Singer S: Chemotherapy is associated with improved survival in adult patients with primary extremity synovial sarcoma. Ann Surg 246: 105-113, 2007

6. Cui Z, Li C, Li X, Zhang Q, Zhang Y, Shao J and Zhou K Sodium selenite $\left(\mathrm{Na}_{2} \mathrm{SeO}_{3}\right)$ induces apoptosis through the mitochondrial pathway in CNE-2 nasopharyngeal carcinoma cells. Int J Oncol 46: 2506-2514, 2015.

7. Rayman MP: Selenium and human health. Lancet 379 : 1256-1268, 2012.

8. Fairweather-Tait SJ, Bao Y, Broadley MR, Collings R, Ford D, Hesketh JE and Hurst R: Selenium in human health and disease. Antioxid Redox Signal 14: 1337-1383, 2011

9. Klein EA: Selenium: Epidemiology and basic science. J Urol 171: S50-S53, 2004

10. Park SH, Kim JH, Chi GY, Kim GY, Chang YC, Moon SK Nam SW, Kim WJ, Yoo YH and Choi YH: Induction of apoptosis and autophagy by sodium selenite in A549 human lung carcinoma cells through generation of reactive oxygen species. Toxicol Lett 212: 252-261, 2012.

11. LiZ, Meng J, Xu TJ, Qin XY andZhou XD: Sodium selenite induces apoptosis in colon cancer cells via Bax-dependent mitochondrial pathway. Eur Rev Med Pharmacol Sci 17: 2166-2171, 2013.

12. Li Z, Shi K, Guan L, Jiang Q, Yang Y and Xu C: Activation of p53 by sodium selenite switched human leukemia NB4 cells from autophagy to apoptosis. Oncol Res 21: 325-331, 2013.

13. Brodin O, Eksborg S, Wallenberg M, Asker-Hagelberg C, Larsen EH, Mohlkert D, Lenneby-Helleday C, Jacobsson H, Linder S, Misra S and Björnstedt M: Pharmacokinetics and toxicity of sodium selenite in the treatment of patients with carcinoma in a phase I clinical trial: The SECAR study. Nutrients 7: 4978-4994, 2015.

14. Gao H, Sun W, Zhao W, Hao W, Leung CH, Lu J and Chen X: Total tanshinones-induced apoptosis and autophagy via reactive oxygen species in lung cancer 95D cells. Am J Chin Med 43: 1265-1279, 2015

15. Kontos CK, Christodoulou MI and Scorilas A: Apoptosis-related BCL2-family members: Key players in chemotherapy. Anticance Agents Med Chem 14: 353-374, 2014.

16. Hirchaud F, Hermetet F, Ablise M, Fauconnet S, Vuitton DA, Prétet JL and Mougin C: Isoliquiritigenin induces caspase-dependent apoptosis via downregulation of HPV16 E6 expressionincervicalcancerCaSkicells.PlantaMed79:1628-1635, 2013.

17. You L, Shou J, Deng D, Jiang L, Jing Z, Yao J, Li H, Xie J, Wang Z, Pan Q, et al: Crizotinib induces autophagy through inhibition of the STAT3 pathway in multiple lung cancer cell lines. Oncotarget 6: 40268-40282, 2015.

18. Xu K, Cai YS, Lu SM, Li XL, Liu L, Li Z, Liu H and Xu P. Autophagy induction contributes to the resistance to methotrexate treatment in rheumatoid arthritis fibroblast-like synovial cells through high mobility group box chromosomal protein 1 . Arthritis Res Ther 17: 374, 2015.
19. Klionsky DJ, Abeliovich H, Agostinis P, Agrawal DK, Aliev G, Askew DS, Baba M, Baehrecke EH, Bahr BA, Ballabio A, et al: Guidelines for the use and interpretation of assays for monitoring autophagy in higher eukaryotes. Autophagy 4: 151-175, 2008 .

20. Ren Y, Huang F, Liu Y, Yang Y, Jiang Q and Xu C: Autophagy inhibition through PI3K/Akt increases apoptosis by sodium selenite in NB4 cells. BMB Rep 42: 599-604, 2009.

21. Králová $V$, Benešová $S$, Cervinka $M$ and Rudolf $E$ : Selenite-induced apoptosis and autophagy in colon cancer cells. Toxicol In Vitro 26: 258-268, 2012.

22. Tsai JP, Lee CH, Ying TH, Lin CL, Lin CL, Hsueh JT and Hsieh YH: Licochalcone A induces autophagy through PI3K/Akt/mTOR inactivation and autophagy suppression enhances Licochalcone A-induced apoptosis of human cervical cancer cells. Oncotarget 6: 28851-28866, 2015.

23. Amaravadi RK, Yu D, Lum JJ, Bui T, Christophorou MA, Evan GI, Thomas-Tikhonenko A and Thompson CB: Autophagy inhibition enhances therapy-induced apoptosis in a Myc-induced model of lymphoma. J Clin Invest 117: 326-336, 2007.

24. Singh BN, Kumar D, Shankar S and Srivastava RK: Rottlerin induces autophagy which leads to apoptotic cell death through inhibition of PI3K/Akt/mTOR pathway in human pancreatic cancer stem cells. Biochem Pharmacol 84: 1154-1163, 2012.

25. Allan LA and Clarke PR: Apoptosis and autophagy: Regulation of caspase-9 by phosphorylation. FEBS J 276: 6063-6073, 2009.

26. Sutter ME, Thomas JD, Brown J and Morgan B: Selenium toxicity: A case of selenosis caused by a nutritional supplement. Ann Intern Med 148: 970-971, 2008.

27. Nuttall KL: Evaluating selenium poisoning. Ann Clin Lab Sci 36: 409-420, 2006.

28. Johnson CC, Fordyce FM and Rayman MP: Symposium on 'Geographical and geological influences on nutrition': Factors controlling the distribution of selenium in the environment and their impact on health and nutrition. Proc Nutr Soc 69: 119-132, 2010.

29. Ho AL, Vasudeva SD, Laé M, Saito T, Barbashina V, Antonescu CR, Ladanyi M and Schwartz GK: PDGF receptor alpha is an alternative mediator of rapamycin-induced Akt activation: Implications for combination targeted therapy of synovial sarcoma. Cancer Res 72: 4515-4525, 2012.

30. Hay N and Sonenberg N: Upstream and downstream of mTOR. Genes Dev 18: 1926-1945, 2004

31. Zhang J, Zhao D, Xie Z and Qi Y: Down-regulation of AKT combined with radiation-induced autophagy and apoptosis roles in MCF-7 cells. Biomed Mater Eng 26 (Suppl 1): S2259-S2265, 2015.

32. Zeng X and Kinsella TJ: Mammalian target of rapamycin and S6 kinase 1 positively regulate 6-thioguanine-induced autophagy. Cancer Res 68: 2384-2390, 2008

33. Majumder PK, Febbo PG, Bikoff R, Berger R, Xue Q, McMahon LM, Manola J, Brugarolas J, McDonnell TJ, Golub TR, et al: mTOR inhibition reverses Akt-dependent prostate intraepithelial neoplasia through regulation of apoptotic and HIF-1-dependent pathways. Nat Med 10: 594-601, 2004.

34. Faghiri $\mathrm{Z}$ and Bazan NG: PI3K/Akt and mTOR/p70S6K pathways mediate neuroprotectin D1-induced retinal pigment epithelial cell survival during oxidative stress-induced apoptosis. Exp Eye Res 90: 718-725, 2010.

This work is licensed under a Creative Commons Attribution-NonCommercial-NoDerivatives 4.0 International (CC BY-NC-ND 4.0) License. 